\title{
Formas de expressão da escalaridade em português
}

\author{
Scalarity expression in Portuguese
}

\author{
Michel Gustavo Fontes ${ }^{1}$ \\ Fábio de Lima Moreira ${ }^{2}$
}

Resumo: Este artigo aborda o fenômeno da escalaridade em português. A partir dos pressupostos teórico-metodológicos da Gramática Discursivo-Funcional (HENGEVELD; MACKENZIE, 2008), objetiva-se descrever o uso expansivo de até e ainda de modo a precisar em que medida esses itens instauram escalas de natureza mais discursivo-pragmática. Com base em Schwenter $(1999 ; 2000 ; 2002)$ e Schwenter e Traugott (2000), os resultados revelam (i) uma correlação entre a expressão de escalaridade e o duplo escopo de até e ainda no Nível Interpessoal, e (ii) uma distinção funcional entre os dois itens - enquanto até funciona como partícula escalar absoluta, ainda se comporta como partícula escalar relativa.

Palavras-chave: Escalaridade. Partículas escalares. Gramática Discursivo-Funcional.

Abstract: This paper offers an account on scalarity expression in Portuguese. Based on Functional Discourse Grammar model (Hengeveld; Mackenzie, 2008), the aim is to describe até and ainda, in their expansive use, in order to determine whether these items trigger discursive-pragmatic scales. Following Schwenter (1999; 2000; 2002) and Schwenter and Traugott (2000), the results reveal (i) a correlation between scalarity expression and the double scope of até and ainda in the Interpersonal Level, and (ii) a functional distinction between these two items - while até functions as an absolute scalar particle, ainda is a relative scalar particle.

Keywords: Scalarity. Scalar particles. Functional Discourse Grammar.

\section{Introdução}

Seguindo uma perspectiva pragmático-discursiva, particularmente os trabalhos de Schwenter (1999; 2000; 2002) e Schwenter e Traugott (2002), este artigo aborda o fenômeno da escalaridade com base em dados do português, especificamente a partir de ocorrências como as dispostas em (1), que exemplificam o uso dos itens até e ainda como partículas aditivas ou inclusivas (cf. KÖNIG, 1991). ${ }^{3}$

\footnotetext{
${ }^{1}$ Universidade Federal de Mato Grosso do Sul, Programa de Pós-Graduação em Letras, Três Lagoas, MS, Brasil. Endereço eletrônico: michel.fontes@ufms.br.

${ }^{2}$ Universidade Federal de Mato Grosso do Sul, Três Lagoas, MS, Brasil. Bolsista da Fundação de Apoio e Desenvolvimento do Ensino, Ciência e Tecnologia do Mato Grosso do Sul. Endereço eletrônico: fabiolima_moreira3@hotmail.com.

${ }^{3}$ Fontes (2016) caracteriza a multifuncionalidade de ainda a partir de quatro distintos usos: ainda fasal, ainda polar, ainda enfático e ainda expansivo. Baião e Arruda (1996) reconhecem dois usos centrais de até: como
} 
(1) A Como vai ficar o relacionamento com o governo estadual, no caso específico com a Oficina Cultural. Na gestão anterior as rivalidades PSDB x PMDB ou Tuga x Tidei prejudicaram parcerias e até a participação da cidade no Mapa Cultural. (19Or:Br:Intrv:Cid)

B O congresso, apesar disso, aprovou propostas pouco realistas e ainda mostrou que a direção da CUT não está coesa. Isso vai prejudicar o desempenho da central daqui para a frente? (19Or:Br:Intrv:ISP)

Nas ocorrências em (1), até e ainda correspondem a mecanismos linguísticos utilizados pelo falante para sinalizar, a seu ouvinte, a necessidade de expansão de sua (do ouvinte) informação pragmática. Esta investigação recorta, então, como objeto de estudo, um uso específico de até e ainda, aqui chamado de expansivo.

Ancorado no aparato teórico-metodológico da Gramática Discursivo-Funcional (doravante GDF), de Hengeveld e Mackenzie (2008), este trabalho objetiva descrever o uso expansivo de ainda e até de modo a precisar em que medida esses dois elementos linguísticos instauram escalas de natureza mais discursivo-pragmática.

Especificamente, intenciona-se mapear as distintas relações de escopo contraídas por até e ainda, em seu uso expansivo, tendo em vista duas hipóteses: (i) a de que as diferentes relações de escopos de até e ainda, em seu uso expansivo, estão correlacionadas à expressão de distintos tipos de escalaridade; e (ii) a de que até e ainda correspondem a diferentes tipos de partículas escalares, fato que os distinguem funcionalmente no interior do sistema linguístico do português.

Para tanto, a pesquisa se vale de ocorrências de uso de até e ainda, extraídas do Corpus do Português (DAVIES; FERREIRA, 2006), ${ }^{4}$ e estrutura-se em quatro seções: a primeira apresenta a noção de escalaridade que subsidiará a análise; a segunda traz uma síntese do modelo da GDF; a terceira, por sua vez, delimita e caracteriza, conforme o modelo da GDF, o objeto de estudo, o uso expansivo de até e ainda; a quarta, por fim, busca correlações possíveis entre o uso expansivo de até e ainda e a expressão de escalaridade. As considerações finais sistematizam os resultados da análise.

\section{Por uma definição de escalaridade}

O estudo da escalaridade remete a trabalhos como de Horn (1972) e Gazdar (1979), que, em perspectiva mais formal, definem o fenômeno levando-se em conta dois aspectos das

preposição (espacial e/ou temporal) e como partícula inclusiva/expansiva. Este artigo, portanto, focaliza, entre os distintos usos de ainda e até no português, aquele que lhes é comum: o uso expansivo.

4 A plataforma pode ser acessada pelo seguinte link: https://www.corpusdoportugues.org/, em sua extensão Gênero/Histórico. Para os efeitos desta pesquisa, utiliza-se ocorrências apenas do século XX. 
proposições griceanas (GRICE, 1987): a máxima conversacional da quantidade e as implicaturas conversacionais. Para esses autores, a escalaridade, de modo geral, associa-se à quantificação e, por conseguinte, à generalização de implicaturas conversacionais.

Nesse sentido, Bakker (1988) define escalaridade enquanto "noção semântica que se

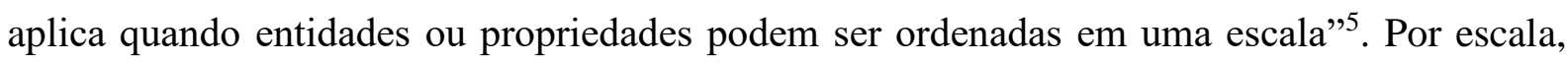
compreende-se o conjunto de expressões (ou alternativas) contrastivas de uma mesma categoria, que podem ser dispostas numa ordem linear de acordo com sua força semântica (cf. KÖNIG, 1991, p. 39). Para Bakker (1988), relações escalares se definem em termos paradigmáticos, já que envolvem relações de substituição, isto é, uma relação em que um dado termo pode ser substituído por outro.

Assim, para que um conjunto de expressões linguísticas do tipo $\left\langle\mathrm{e}_{1}, \mathrm{e}_{2}, \mathrm{e}_{3} \ldots . \mathrm{e}_{\mathrm{n}}>\right.$ se configure como uma escala, duas condições devem ser preenchidas: (i) se $e_{1}$ é substituída por $\mathrm{e}_{2}$ em um modelo sentencial $\mathrm{S}\left(\right.$ ), obtém-se uma sentença bem formada; (ii) $\mathrm{S}\left(\mathrm{e}_{1}\right)$ implica $\mathrm{S}\left(\mathrm{e}_{2}\right), \mathrm{S}\left(\mathrm{e}_{2}\right)$ implica $\mathrm{S}\left(\mathrm{e}_{3}\right), \mathrm{S}\left(\mathrm{e}_{3}\right)$ implica $\mathrm{S}\left(\mathrm{e}_{4}\right)$, etc., mas nunca o contrário. König (1991) oferece, como exemplo, a escala <all, many, some, few $\rangle$, de modo que (i) all em all members attended the meeting pode ser substituído por many sem afetar sua gramaticalidade (many members attended the meeting); (ii) $\mathrm{S}($ all) implica $\mathrm{S}$ (many), $\mathrm{S}$ (many) implica $\mathrm{S}$ (some), $\mathrm{S}($ some $)$ implica $\mathrm{S}($ few $)$, mas não o contrário.

Para além dessas escalas de natureza mais semântica, cujas alternativas contrastivas são ordenadas em termos de implicações lógicas e/ou semânticas, Schwenter (1999) e Schwenter e Traugott (2000) reconhecem outros dois tipos de escalas: as escalas pragmáticas e as escalas retóricas.

As escalas pragmáticas compõem-se de expressões alternativas ordenadas segundo implicações pragmáticas. A definição de uma escala de natureza mais pragmática remonta ao trabalho de Fauconnier (1975, p. 353), para quem, o uso do adjetivo delicious no superlativo em (2) não só significa que Tommy come qualquer tipo de comida com exceção das mais deliciosas, mas também implica que Tommy se recusa a comer qualquer tipo de comida. Segundo o autor, esse tipo de raciocínio se dá com base em uma escala pragmaticamente estabelecida, em que se ordenam comidas desde as menos, até as mais deliciosas.

(2) Tommy will not eat the most delicious food.

\footnotetext{
${ }^{5}$ No original: "Scalarity is a semantic notion which applies when entities or properties can be ordered on a scale" (BAKKER, 1988, p. 28).
} 
Em escalas pragmáticas, as implicações entre seus membros não se dão mais em termos lógicos e/ou semânticos (como nas escalas semânticas), mas em termos pragmáticos, baseando-se nas expectativas do falante em relação ao mundo, ou melhor, as implicações partem das suposições e dos conhecimentos dos usuários da língua em relação ao mundo. Um segundo exemplo, adaptado de Schwenter e Traugott (2000), é a sentença em (3), em que o uso do adjetivo difícil no superlativo relativo (mais difícil) pode implicar (ou pressupor), tendo em vista os conhecimentos (de mundo) sobre sistemas de avaliação escolar, que João também tirou dez em outras provas, naquelas menos difíceis ou mais fáceis.

João tirou dez na prova mais dificil.

Já as escalas retóricas, também denominadas de argumentativas, apresentam membros (ou alternativas) ordenados conforme a força que cumprem para dar suporte ao objetivo retórico (ou argumentativo) do falante ao construir seu discurso. Segundo Schwenter (1999) e Schwenter e Traugott (2000), esse tipo de escalaridade é semelhante à escalaridade pragmática, pois ambas se baseiam em expectativas e premissas do falante; a diferença recai no fato de que, em escalas retóricas, não é necessário que haja uma relação implicativa entre as alternativas, uma vez que o escalonamento entre seus membros se dá em termos de força retórica (ou argumentativa) para que o falante cumpra seus propósitos comunicativos.

Schwenter (1999, p. 189) ilustra esse tipo de escala com base nas sentenças em (4). Pensando que, numa interação entre A e B, ao fazer referência ao quão brilhante é J, diz-se (4a); isso soaria um pouco estranho, já que, numa escala argumentativa que ordena as línguas em questão, even situa Spanish num ponto mais extremo que Russian, o que contraria as expectativas de um falante nativo do inglês. Já uma sentença como (4b), em que even situa Russian numa posição mais extrema que Spanish, traz uma configuração que escalona Spanish e Russian numa relação que sustenta mais eficazmente o argumento de que $J$ é uma pessoa brilhante.

(4) A J speaks Russian and she even speaks Spanish.

B J speaks Spanish and she even speaks Russian.

Nas línguas em geral, há elementos linguísticos, comumente chamados de partículas escalares, que veiculam esse tipo de fenômeno, selecionando alternativas que são ordenadas, de alguma maneira, em relação a algum valor. A partícula even, do inglês, é um exemplo (cf. (4) e (5)). Em (5), a aplicação de even à sentença faz pressupor que John reads something 
other than Shakespeare e, além disso, ordena essas outras variáveis pressupostas em uma escala, por exemplo uma escala de probabilidade, sendo que essas variáveis incluídas se posicionam abaixo da variável dada na sentença (ou seja, os outros autores que John lê estão numa posição inferior a Shakespeare numa escala de probabilidade de leitura).

$$
\text { John even reads SHAKESPEARE. (KÖNIG, 1991, p. 37) }
$$

Schwenter $(2000 ; 2002)$ distingue as partículas escalares em relativas e absolutas. Enquanto uma partícula escalar absoluta marca necessariamente o ponto final de uma escala, situando uma informação em uma posição extrema dentro de uma dada escala, uma partícula escalar relativa não assinala inerentemente o ponto final e extremo de uma escala, apenas situa uma informação em posição superior a outra.

Para exemplificar essa distinção, toma-se a análise de Schwenter (2000; 2002) em relação às partículas espanholas incluso e hasta, exemplificadas em (6). Ambas compartilham duas propriedades pragmáticas: (i) uma natureza aditiva, pois implicam que, além de Sara, outros estudantes foram à aula, e (ii) uma natureza escalar, já que posicionam Sara em algum ponto superior da escala pragmática que ordena os estudantes conforme as possibilidade de irem (ou não) à aula.

(6) A Incluso Sara vino a classe hoy. (SCHWENTER, 2000, p. 170)

B Hasta Sara vino a classe hoy. (SCHWENTER, 2000, p. 170)

A distinção entre incluso e hasta recai sobre o tipo de marcação escalar: incluso não necessariamente assinala um ponto fixo na escala pragmática, isto é, não situa inerentemente Sara no ponto final da escala que ordena os alunos conforme a probabilidade de irem à aula, colocando-a apenas num ponto superior; hasta, ao contrário, marca, necessariamente, um ponto final na escala pragmática, isto é, localiza inerentemente Sara no ponto final e extremo da escala que ordena os alunos conforme probabilidade de irem à aula. Incluso, então, configura uma partícula escalar relativa, e hasta, uma partícula escalar absoluta.

Inspirado centralmente em Schwenter (1999; 2000; 2002) e Schwenter e Traugott (2000), este trabalho se pergunta: (i) que tipos de escalas são instauradas por até e ainda, em seu uso expansivo?; (ii) como isso se correlaciona ao escopo desses itens no Nível Interpessoal?; e (iii) a que tipo de partículas escalares até e ainda correspondem?. 


\section{A Gramática Discursivo-Funcional}

A GDF, conforme concebida por Hengeveld e Mackenzie (2008), corresponde ao Componente Gramatical de uma teoria mais geral da interação verbal. Esse Componente Gramatical articula-se a outros três componentes não linguísticos: o Componente Conceitual (força motriz do Componente Gramatical e responsável pelas intenções comunicativas do falante), o Componente Contextual (que abriga as informações relativas aos contextos linguístico e situacional) e o Componente de Saída (responsável por traduzir os inputs do Componente Gramatical em material acústico, escrito e/ou simbólico).

De modo a implementar dinamicamente o modelo, Hegenveld e Mackenzie (2008) defendem que o processo de produção de uma expressão linguística é descendente (ou topdown), de maneira que a intenção comunicativa do falante, conforme elaborada no Componente Conceitual, recebe material linguístico, no Componente Gramatical, até chegar à articulação por meios acústicos, escritos ou simbólicos no Componente de Saída.

No interior do Componente Gramatical, dois processos estão envolvidos na materialização linguística da intenção comunicativa do falante: a formulação e a codificação. Enquanto a formulação é responsável por converter representações conceituais em representações pragmáticas e semânticas, a codificação se responsabiliza por estruturar formalmente, em unidades morfossintáticas e/ou fonológicas, as representações pragmáticas e semânticas advindas da formulação.

A formulação sustenta, então, os dois primeiros níveis de análise do modelo: o Interpessoal e o Representacional. O Nível Interpessoal se estrutura, essencialmente, a partir do reconhecimento de propriedades retóricas e pragmáticas próprias à interação verbal e, assim, lida com os aspectos formalmente codificados que refletem o papel de uma unidade linguística no interior da interação entre falante(s) e ouvinte(s).

A representação em (7) esquematiza a organização hierárquica em camadas do Nível Interpessoal: o Movimento (M), camada mais alta, pode conter um ou mais Atos Discursivos (A), que, por sua vez, constitui-se de uma Ilocução (F), dos Participantes (P) - Falante $\left(\left(\mathrm{P}_{1}\right)_{\mathrm{S}}\right)$ e Ouvinte $\left(\left(\mathrm{P}_{2}\right)_{\mathrm{A}}\right)$ - e de um Conteúdo Comunicado $(\mathrm{C})$, nucleado por Subatos de Referência (R) e/ou de Atribuição (T).

$$
\left(\mathrm{M}_{1}:\left[\left(\mathrm{A}_{1}:\left[\left(\mathrm{F}_{1}\right)\left(\mathrm{P}_{1}\right)_{\mathrm{S}}\left(\mathrm{P}_{2}\right)_{\mathrm{A}}\left(\mathrm{C}_{1}:\left[\left(\mathrm{T}_{1}\right)_{\{\Phi\}} \ldots\left(\mathrm{T}_{1+\mathrm{N}}\right)_{\{\Phi\}}\left(\mathrm{R}_{1}\right)_{\{\Phi\}}\right]\left(\mathrm{C}_{1}\right)_{\{\Phi\}}\right)\right]\left(\mathrm{A}_{1}\right) \ldots\left(\mathrm{A}_{1+\mathrm{N}}\right)_{\{\Phi\}}\right]\left(\mathrm{M}_{1}\right)\right)\right.
$$

O Nível Representacional é responsável por questões semânticas envolvidas na formulação linguística, sendo semântica compreendida em duas vias: (i) o modo como as 
expressões referenciam o mundo extralinguístico que descrevem, e (ii) os significados de unidades lexicais e de unidades complexas isolados de seu uso na comunicação.

Esse nível se organiza a partir da distinção de categorias semânticas definidas em termos ontológicos, conforme ilustra (8): o Conteúdo Proposicional (p), camada mais alta desse nível, pode conter um ou mais Episódios (ep), que são compostos de Estados-de-Coisas coerentemente relacionados em termos de tempo, espaço e indivíduo. Um Estado-de-Coisas (e), por sua vez, se organiza em termos de Propriedade Configuracional $\left(\mathrm{f}^{\mathrm{c}}\right)$, no interior da qual se reconhece a Propriedade Lexical (f). Além dessas camadas, o Nível Representacional conta com outras categorias semânticas como Indivíduo (x), Localização (1), Tempo (t), Modo (m), Razão (r) e Quantidade (q).

$$
\left.\left(\mathrm{p}_{1}:\left[\left(\mathrm{ep}_{1}:\left[\left(\mathrm{e}_{1}:\left[\left(\mathrm{f}_{1}^{\mathrm{c}}\right)_{1}:\left[\left(\mathrm{f}_{2}\right)^{\mathrm{n}}\left(\mathrm{x}_{1}\right)_{\Phi} \ldots\left(\mathrm{x}_{1+\mathrm{n}}\right)_{\Phi}\right]\left(\mathrm{f}^{\mathrm{c}}{ }_{1}\right)\right) \ldots\left(\mathrm{f}^{\mathrm{c}}{ }_{1+\mathrm{n}}\right)\left(\mathrm{e}_{1}\right)_{\Phi}\right]\right) \ldots\left(\mathrm{e}_{1+\mathrm{n}}\right)_{\{\Phi}\right]\left(\mathrm{ep}_{1}\right)\right) \ldots\left(\mathrm{ep}_{1+\mathrm{n}}\right)_{\{\Phi\}}\right]\left(\mathrm{p}_{1}\right)\right)
$$

A partir do input proveniente da formulação, fica a cargo do Nível Morfossintático a codificação morfossintática, que transforma o conteúdo pragmático-semântico proveniente dos níveis Interpessoal e Representacional em unidades morfossintaticamente analisáveis, representadas em (9). Sua camada mais alta é a Expressão Linguística (Le), no interior da qual se distinguem unidades como Oração $(\mathrm{Cl})$, Sintagma $(\mathrm{Xp})$, que pode ser Nominal (Np), Adjetival (Adjp), Verbal (Vp) ou Adverbial (Advp), e/ou Palavra (Xw), que pode ser Lexical (Lw) ou Gramatical (Gw).

$$
\left.\left(\mathrm{Le}_{1}:\left[\mathrm{Cl}_{1}:\left[(\mathrm{Xw})\left(\mathrm{Xp}_{1}:\left[(\mathrm{Xw})\left(\mathrm{Xp}_{2}\right)\left(\mathrm{Cl}_{2}\right)\right]\left(\mathrm{Xp}_{1}\right)\right)\left(\mathrm{Cl}_{3}\right)\right]\left(\mathrm{Cl}_{1}\right)\right)\right]\left(\mathrm{Le}_{1}\right)\right)
$$

O Nível Fonológico, por fim, encarrega-se da codificação fonológica, oferecendo, à expressão linguística, representações fonêmicas baseadas em oposições fonológicas binárias. Esse nível toma o input proveniente dos outros três níveis e provê input para a articulação, sob responsabilidade do Componente de Saída.

O esquema em (10) revela o modo como cada uma das camadas que compõem os níveis acima caracterizados se estrutura. A variável $\mathrm{v}_{1}$ representa a camada relevante para a descrição linguística, e, a essa camada, pode ser aplicado um conjunto de primitivos, blocos construtores combinados conforme as regras de formulação e de codificação da gramática da língua. Assim, as camadas de cada um dos níveis da GDF podem ser restringidas por primitivos de natureza lexical, como um núcleo ou um modificador $(\sigma)$, ou podem ser 
especificadas por primitivos de natureza gramatical, como um operador $(\pi)$ ou uma função $(\Phi)$.

$$
\left(\pi \mathrm{v}_{1}:\left[\text { núcleo }\left(\mathrm{v}_{1}\right)_{\Phi}\right]:\left[\sigma\left(\mathrm{v}_{1}\right)_{\Phi}\right]\right)
$$

Relações de escopo, no âmbito da GDF, podem ser definidas e mapeadas em termos de camadas dos níveis da formulação (cf. HENGEVELD, 2017). Assim, elementos hierárquicos dos níveis Interpessoal e Representacional, como modificadores e operadores, podem escopar qualquer camada que compõe esses níveis. É com foco central nas diferentes relações de escopo contraídas por até e ainda, em seu uso expansivo, que se busca precisar a natureza das escalas por eles instauradas.

\section{Delimitando o objeto de estudo}

Segundo Hengeveld e Mackenzie (2008, p. 46), o Nível Interpessoal da GDF se organiza tendo em vista que falante e ouvinte interagem entre si com um propósito em mente, e esse propósito determina quais estratégias (retóricas ou pragmáticas) serão adotadas pelo falante para atingir seus objetivos comunicativos. Em termos de estratégias pragmáticas, especificamente, as línguas podem mobilizar recursos linguísticos diversos que modelam a mensagem do falante tendo em vista suas expectativas em relação ao estado mental do ouvinte. As ocorrências em (11) e (12) ilustram que os dois objetos de estudo aqui tomados os itens até e ainda em seu uso expansivo - são unidades formais que codificam ações pragmáticas do falante ao construir seu discurso. Assim, até e ainda, em (11) e (12), correspondem, no interior do modelo da GDF, a primitivos do Nível Interpessoal.

(11) A JC - Você não teve medo de não ter suas opiniões respeitadas, uma vez que os moradores são mais velhos que você? Gisella - A princípio sim e tiveram até algumas resistências. Mas o pessoal foi descobrindo que eu tinha vontade de fazer um trabalho sério. As dívidas eram altas e quando as contas começaram a ficar em ordem, aumentou a minha credibilidade. (19Or:Br:Intrv:Cid)

NI: $\left(\mathrm{R}_{1}\right.$ : - algumas resistências $\left.-\left(\mathrm{R}_{1}\right)_{\text {ContExp }}\right)$

NM: (Cl: [(Vp: tiveram (Vp)) (Gw: atéPart $(\mathbf{G w}))(\mathrm{Np}$ : algumas resistências (Np))] (Cl))

B O PMDB sempre fez política e até tinha uma visão diferente nesse sentido, o PMDB muitas vezes cooptava deputados. Nós tivemos coisas diferentes na época em que o partido era governo e eu era deputado. O PMDB cooptou quatro dos nove deputados do PSDB na época e esses deputados transferiram para o PMDB. (19Or:Br:Intrv:Cid)

NI: $\left(A_{1}:\left(C_{1}\right.\right.$ : - tinha uma visão diferente nesse sentido - $\left.\left.\left(\mathrm{C}_{1}\right)_{\text {ContExp }}\right)\left(\mathrm{A}_{1}\right)\right)$

NM: $(\mathrm{Cl}$ : $[(\mathbf{G w}$ : atépart $(\mathbf{G w}))(\mathrm{Vp}$ : tinha $(\mathrm{Vp}))(\mathrm{Np}$ : uma visão diferente nesse sentido $(\mathrm{Np}))](\mathrm{Cl}))$ 
Uma primeira propriedade pragmática subjacente ao uso de até e ainda, em (11) e (12), é a da saliência informacional. Nos termos de Travaglia (2006), são elementos linguísticos de marcação de revelo positivo, já que, no âmbito do processamento da informação materializada textualmente, situam determinadas porções textuais em um plano mais elevado, colocando-as, assim, em destaque e em proeminência em relação a outras.

De modo alinhado à marcação de relevo positivo, até e ainda operam ações discursivas específicas do falante ao construir sua mensagem, constituindo instruções com que o falante deseja proceder para que seu ouvinte receba sua mensagem. De modo geral, até e ainda, em (11) e (12), materializam linguisticamente a ação comunicativa do falante em demonstrar a seu(s) ouvinte(s) a necessidade de expansão de sua (do ouvinte) informação pragmática a partir das informações já colocadas no registro gradualmente construído junto ao componente contextual.

Em (11), a saliência e a expansão informacional operada por até recai sobre dois tipos de unidades interpessoais. Em (11a), até escopa o Subato Referencial algumas resistências, salientando-o, de modo que, ao responder afirmativamente sobre ter medo quanto ao respeito a suas opiniões, o falante expande sua declaração evocando a referência a algumas resistências. Em (11b), por outro lado, o escopo de até recai sobre o Conteúdo Comunicado do Ato Discursivo prefaciado pelo relator $e$ : após a declaração de que o PMDB sempre fez política, o falante opta por assinalar, para seu ouvinte, a necessidade de se expandir tal informação, ressaltando o conteúdo a ser comunicado pelo Ato declarativo seguinte (de que $o$ PMDB tinha uma visão diferente nesse sentido).

(12) a Muitos eram pequenos papéis, que podiam ser dobrados. Mas existia basicamente um núcleo de atores-sócios, que eram a essência da companhia. Havia ainda um grupo de atores contratados e também os aprendizes. Quando entrava um, ele era aprendiz do fulano de tal, daquele ator que transmitia tudo o que sabia a respeito de interpretação. (19Or:Br:Intrv:ISP)

NI: (-id, $+\mathrm{s} \mathrm{R}_{1}$ : - grupo de atores contratados $\left.-\left(\mathrm{R}_{1}\right)_{\text {ContExp }}\right)$

NM: (Cl: [(Vp: - havia - (Vp)) (Gw: aindapart (Gw)) (Np: - um grupo de atores contratados $-(\mathrm{Np}))](\mathrm{Cl}))$

b JC - Dá para sobreviver sem promoção? Fortunato - Não. Antigamente, as liqüidaçoes eram anuais, passaram a semestrais e, hoje, têm de ser semanal. A indústria está estocada, ela oferece um lote, dá prazo e ainda paga a propaganda. A própria indústria traz a oferta. As vezes, há duas ou três no mesmo dia. As indústrias chegam a pagar de $80 \%$ a $100 \%$ a propaganda nos jornais.

NI: $\left(\mathrm{A}_{1}\right.$ : $\left(\mathrm{C}_{1}\right.$ : - paga a propaganda $\left.\left.-\left(\mathrm{C}_{1}\right)_{\mathrm{ContExp}}\right)\left(\mathrm{A}_{1}\right)\right)$

NM: (Cl: [(Gw: aindapart $(\mathbf{G w}))(\mathrm{Vp}$ : paga $(\mathrm{Vp}))(\mathrm{Np}$ : a propaganda $(\mathrm{Np}))](\mathrm{Cl}))$ 
Em (12a), ainda salienta a referência a um grupo de atores contratados, destacando, assim, uma parte específica da totalidade ali comunicada, especificamente o Subato Referencial um grupo de atores contratados. Pode-se observar, nessa ocorrência, que o falante assume que seu Ouvinte sabe da existência de atores-sócios na companhia, mas também reconhece que a existência de atores contratados não faz parte de sua informação pragmática. Seu movimento discursivo, ao fazer uso de ainda, é indicar ao ouvinte a necessidade de acrescentar tal informação ao seu conjunto de conhecimentos sobre os atores da companhia.

Já em (12b), o falante coloca em proeminência a totalidade a ser comunicada pelo Ato Discursivo introduzido pela conjunção aditiva $e$, de modo que ainda destaca o Conteúdo Comunicado pagar a propaganda. Ao explicar alguns motivos que justificam o abandono de sua carreira de jogadora, a falante elucida seus feitos na época, como seu trabalho como treinadora da equipe do bauruense e a atuação como atleta em alguns jogos, sendo esta última informação sinalizada, por meio de ainda, como uma expansão informacional a partir do núcleo de informações que se vinha construindo anteriormente e um acréscimo de informação ao conjunto de conhecimentos do ouvinte.

A partir dos dados acima descritos, observa-se que o uso de até e de ainda, além de marcar o estatuto mais saliente de uma informação, sinaliza linguisticamente que a informação ali evocada (seja um Subato, seja um Conteúdo Comunicado) deve ser encarada como uma expansão ou um acréscimo a partir do que se registrou anteriormente. Até e ainda, portanto, são estratégias de vinculação pragmática entre unidades interpessoais que compõem a mensagem construída pelo falante. Trata-se, assim, de marcadores de função pragmática.

Nota-se, além disso, que até e ainda assinalam certa contraposição, no âmbito pragmático da interação verbal, entre a informação por eles introduzida e uma ou mais informações disponíveis contextualmente. Em (11a), a evocação do referente algumas resistências gera certo contraste com qualquer outra situação ali implicada e decorrente de Gisella tornar-se síndica; já em (12a), a inserção do referente um grupo de atores contratados se contrapõe paralelamente ao Subato Referencial um núcleo de atores-sócios, já situado no contexto anterior. Por fim, em (11b) e (12b), os Conteúdos Comunicados evocados nos Atos Discursivos encabeçados por até e ainda contrastam com os conteúdos de Ato(s) anterior(es). Esse contraste, ou contraposição, que se nota em (11) e (12), pela aplicação de até e ainda a um Subato Referencial ou a um Conteúdo Comunicado, tem por base uma quebra de expectativa, a qual, por sua vez, correlaciona-se ao tipo de marcação escalar veiculada pelo uso dos itens linguísticos (o que será explorado na próxima seção). 
A GDF, no Nível Interpessoal, distingue três tipos de funções pragmáticas: Tópico, Foco e Contraste. ${ }^{6}$ A função Contraste assinala o desejo do falante em contrastar as diferenças entre Conteúdos Comunicados ou entre um Conteúdo Comunicado e informações disponíveis contextualmente. Pezatti (2014) distingue três tipos de Contraste: (i) Contraste Expansivo, que, codificado por operadores como também e além disso, assinala a adição de uma informação a outra pressuposta ou já mencionada; (ii) Contraste Restritivo, que, codificado por operadores como apenas e só, corrige a informação pragmática do ouvinte, restringindo um conjunto de itens pressupostos àqueles que considera adequados; e (iii) Contraste Seletivo, que, codificado por operadores como principalmente e sobretudo, seleciona uma peça de informação como mais correta e adequada para integrar o conhecimento do ouvinte. Com base nessa tipologia, e levando em conta as propriedades funcionais subjacentes a até e ainda em seu uso expansivo (cf. (11) e (12)), este trabalho trata esses itens como mecanismos de marcação da função pragmática Contraste Expansivo (ContExp).

No Nível Morfossintático, até e ainda são codificados como Palavras Gramaticais $(\mathrm{Gw})$ e integram o padrão da Oração $(\mathrm{Cl})$. As diferentes relações de escopo contraídas pelos itens determinam seu posicionamento: quando escopam o Subato Referencial, até e ainda se posicionam, conforme o Princípio de Integridade de Domínio, antes do Sintagma Nominal (Np) que codifica o Subato Referencial por eles escopado; já quando seu escopo é o Conteúdo Comunicado, até e ainda se posicionam na margem esquerda da Oração, nas posições iniciais.

Em síntese, esta seção demonstra que até e ainda, em seu uso expansivo, correspondem a marcadores gramaticais da função pragmática Contraste Expansivo e podem contrair, no interior do Nível Interpessoal, duas relações de escopos distintas, com o Subato Referencial e com o Conteúdo Comunicado.

\section{Duas formas de expressão da escalaridade em português}

A partir das propriedades descritas na seção anterior, esta seção procura explorar o modo como o uso expansivo de até e ainda pode instaurar escalas de natureza mais pragmático-discursiva. Dessa forma, a análise, nesta última seção, centra sua atenção nas relações de escopo contraídas por até e ainda em termos de camadas do Nível Interpessoal.

\footnotetext{
${ }^{6}$ Segundo a GDF, enquanto a função pragmática Tópico é atribuída a um Subato que assinala o modo como o Conteúdo Comunicado se relaciona ao registro construído gradualmente no Componente Contextual, a função Foco se atribui a um Subato que assinala a seleção estratégica operada pelo falante de informação nova para preencher uma lacuna na informação pragmática do ouvinte ou para corrigir uma informação do ouvinte.
} 


\section{O item até}

$\mathrm{Na}$ ocorrência em (13), o uso de até, enquanto marcador da função pragmática Contraste Expansivo (ContExp), assemelha-se ao uso da partícula escalar hasta em espanhol (cf. SCHWENTER, 2000; 2002).

(13) JC - Como é o apoio da família? Oshima - Eu estou desamparado, ninguém está me ajudando e até a minha advogada não acredita em mim. Só quer saber de dinheiro. Para ela, a pena que recebi agora está boa. Não é assim, eu estou sozinho. (19Or:Br:Intrv:Cid)

NI: (+id, +s $\mathrm{R}_{1}$ : - minha advogada - $\left.\left(\mathrm{R}_{1}\right)_{\text {ContExp }}\right)$

O escopo de até, em (13), recai sobre o Subato Referencial a minha advogada $\left(\mathrm{R}_{1}\right)$. Ao demonstrar a situação de desamparo familiar a que está sujeito, o falante faz uso de até para assinalar, a seu ouvinte, a inclusão do referente minha advogada entre aqueles que não acreditam nele, ou seja, o uso de até faz pressupor que outras pessoas, além da advogada, também não acreditam nele. Portanto, até, ao escopar o Subato Referencial, instaura uma escala pragmática cujos membros se ordenam conforme implicações baseadas em expectativas e/ou suposições dos usuários da língua em relação mundo.

Além disso, até marca, dentro da escala ali implicada, um ponto fixo para o referente minha advogada, situando-o, especificamente, no extremo superior dessa escala, isto é, o Subato Ferencial a minha advogada está no ponto mais levado e extremo da escala que ordena as pessoas que não acreditam no falante. Seguindo, então, Schwenter (2000; 2002), pode-se caracterizar até, em (13), como uma partícula escalar absoluta.

O mesmo se aplica às ocorrências em (14): até, com escopo sobre Subatos Referenciais, assinala escalas pragmáticas e situa o referente por ele escopado no ponto extremo e mais superior dessa escala.

(14) a O governo diminuiu investimentos para enxugar o máximo possível os gastos, para não emitir e aumentar a inflação, e deu início ao programa de privatização das estatais. Na verdade, tudo começou com Collor. Mas, antes de ser ação prática, é uma discussão política. No bojo da privatização, veio até a necessidade de não se investir em negócio que iria ser vendido. (19Or:Br:Intrv:Com)

NI: (+is, + s $R_{1}$ : - necessidade de não se investir em negócio que iria ser vendido $\left.\left(\mathrm{R}_{1}\right)_{\text {ContExp }}\right)$

b Estamos apenas no segundo dia e seria muito precipitado falar qualquer coisa. $\mathrm{Na}$ verdade, conhecemos muito pouco do que se faz no Nordeste e temos uma semana pela frente. Agora é bom deixar claro que não faremos restrição a nenhuma modalidade. Poderemos premiar o clássico, o moderno, o contemporâneo, o popular, o folclórico e até a dança de salão. As indicações do primeiro semestre saem ainda este mês e o resultado final será em dezembro.

NI: (+is, + s R : - dança de salão - $\left.\left(\mathrm{R}_{1}\right)_{\text {ContExp }}\right)$ 
Em (14a), ao tratar da privatização de estatais a partir do governo Collor, o falante insere a referência à necessidade de não se investir em negócio que iria ser vendido, e a aplicação de até a esse Subato Referencial faz pressupor outras consequências decorrentes da privatização, de modo que a necessidade de não se investir em negócio que iria ser vendido ocupa posição superior a qualquer outro membro dessa escala de prováveis consequências.

Já em (14b), até escopa o último referente (o Subato Referencial a dança de salão) da lista que compõe o complemento do verbo premiar, sinalizando, então, o acréscimo de mais um membro ao conjunto de modalidades culturais a serem premiadas. Assim, em (14b), os membros que formam a escala pragmática ali não ficam subentendidas (como ocorre com (13) e (14a)), mas estão expressos no próprio contexto linguístico, e até assinala, como ponto extremo dessa escala, a dança de salão.

Nota-se, assim, que, ao implicar escalas de natureza pragmática, sustentadas com base em premissas e expectativas dos falantes em termos de seus conhecimentos de mundo, e ao pontuar a posição extrema do Subato Referencial evocado em relação aos outros membros (explícitos ou implícitos) da escala, o uso de até expansivo traz, para o enunciado, um significado contrastivo, por quebra de expectativa. Em (13), particularmente, verifica-se bem essa questão: a quebra de expectativa gerada pelo enunciado linguístico sustenta-se na posição mais extremada, dentro da escala implicada, assinalada por até ao referente minha advogada, quem, pelo conhecimento de mundo compartilhado, deve representar os interesses de seus clientes e, em tese, garantir a confiabilidade de seus posicionamentos.

Na ocorrência em (15), até amplia seu escopo para o Conteúdo Comunicado. Ao retratar sua estadia no México, o Movimento do falante se constitui de três Atos: os dois primeiros $\left(\mathrm{A}_{1} \mathrm{e} \mathrm{A}_{2}\right)$ se combinam, numa relação equipolente, por meio da conjunção $e$, e o terceiro $\left(\mathrm{A}_{3}\right)$ justifica a asserção do segundo Ato. Ao escopar o Conteúdo Comunicado do segundo Ato, até sinaliza a inclusão de um conteúdo mais saliente para os propósitos argumentativos do falante na ação comunicativa desenvolvida no interior desse Movimento.

(15) O nosso encontro verdadeiro deu-se em Cuba. Os outros não tiveram importância. Encontro de olhos nos olhos, em que cada um de nós se olhou por dentro. Um encontro daqueles que deixa marcas indeléveis. Depois do Golpe de 1964 saí exilado para o México, mas já com a intenção de ir para Cuba. Guardo as melhores recordações do México e do seu povo e até poderia ter ficado por lá, pois havia a probabilidade de ir, como professor, para a Universidade Autônoma. Fui para Cuba e, através de um amigo comum, o Victor Rico Galán, jornalista da revista Siempre, acertei esse encontro. (19Or:Br:Intrv:Com)

NI: $\left(\mathrm{M}_{1}\right.$ : $\left[\left(\mathrm{A}_{1}\right.\right.$ : - guardo as melhores recordações do México e do seu povo - $\left.\left(\mathrm{A}_{1}\right)\right)\left(\mathrm{A}_{2}\right.$ : até poderia ter ficado por lá - $\left.\left(\mathrm{A}_{2}\right)\right)\left(\mathrm{A}_{3}\right.$ : - havia a probabilidade de ir, como professor, para a Universidade Autônoma - $\left.\left.\left.\left.\left(\mathrm{A}_{3}\right)_{\text {Motiv }}\right)\right)\right]\left(\mathrm{M}_{1}\right)\right) \rightarrow\left(\mathbf{A}_{2}:\left(\mathbf{C}_{\mathbf{1}}\right.\right.$ : - poderia ter ficado por lá $\left(\mathbf{C}_{1} \underline{\underline{\text { ContExp }}}_{\left.\left(\mathbf{A}_{2}\right)\right)}\right.$ 
Com base em Lenker (2010), verifica-se, em (15), que a adição não se dá de forma pura (em que somente se juntam novas informações, sem implicar qualquer outro valor ou significado), mas sim de forma impura, em que a junção entre as orações é reforçada por até. Assim, na coordenação aditiva em (15), o uso de até sinaliza que o Conteúdo Comunicado evocado pelo segundo Ato Discursivo, introduzido por $e$, representa um argumento que reforça a direção argumentativa tomada pelo falante já no Ato anterior, e, assim, instaura-se uma escala entre os dois argumentos evocados pelos dois primeiros Atos, de modo que, considerando os propósitos retóricos do falante em seu Movimento, o argumento evocado por $\mathrm{A}_{2}$ ocupa posição mais extrema e superior em relação ao argumento de $\mathrm{A}_{1}$.

Até, portanto, ao escopar Conteúdos Comunicados, assinala escalas retóricas, ou argumentativas, e funciona como partícula escalar absoluta. Isso também se aplica aos dados dispostos em (16) abaixo.

(16) a Nesse caso, talvez o governo resolva dar uma alimentada na economia. Acredito até que o governo vá fazer isso através da construção civil. Estimulada, irá girar a roda da economia. (19Or:Br:Intrv:Com)

NI: $\left(A_{1}\right.$ : $\left(C_{1}\right.$ : - que o governo vá fazer isso através da construção civil - $\left.\left.\left(\mathrm{C}_{1}\right)_{\text {ContExp }}\right)\left(A_{1}\right)\right)$

b JC - Esses votos vindos do grupo de oposição já eram esperados, ou foi uma coisa de momento? Valle - Tínhamos conversado com todos. Até imaginávamos que seriam 14 votos. O Izzo (prefeito Antônio Izzo Filho (PPB) chegou até a comentar, pois imaginávamos que seriam 14 votos, mas, na hora, foram 13 votos. (19Or:Br:Intrv:Cid)

NI: $\left(A_{1}:\left(C_{1}\right.\right.$ : - imaginávamos que seriam 14 votos $\left.\left.-\left(\mathrm{C}_{1}\right)_{\text {ContExp }}\right)\left(A_{1}\right)\right)$

Em (16a), até se encontra em um contexto de subordinação completiva, já que seu escopo está sobre toda a oração que completa o sentido do predicado acreditar. No Nível Interpessoal, a oração completiva corresponde a um Conteúdo Comunicado, e até codifica a atribuição, no Nível Interpessoal, de Contraste Expansivo a esse Conteúdo Comunicado. A aplicação de até a esse Conteúdo Comunicado faz com que, em uma escala de natureza retórica, esse argumento ganhe especial proeminência, entre todos os outros argumentos ali apresentados, para os propósitos comunicativos do falante.

Em (16b), do mesmo modo, o Conteúdo Comunicado evocado pelo segundo Ato $\left(\mathrm{A}_{2}\right)$, sob escopo de até, situa-se num ponto mais superior e extremo, numa escala retórica, que o conteúdo do Ato anterior, que dá início à reação do falante. Assim, o falante, ao empregar até, não só sinaliza linguisticamente que a informação ali evocada deve ser encarada como uma expansão ou um acréscimo a partir do que se registrou anteriormente, mas também, e principalmente, marca o estatuto mais saliente dessa informação, em relação a todas as outras anteriormente colocadas, para sustentar os seus propósitos retóricos. 
Em (15) e (16), também se pode notar contraste ou contraposição entre os Conteúdos Comunicados ali vinculados. De certa forma, até, ao escalonar os argumentos ali evocados e situar um deles como o mais saliente para os propósitos argumentativos do falante, implica, ali, uma relação contrastiva (em termos retóricos) entre os segmentos articulados.

Em suma, defendem-se, aqui, dois pontos em relação ao uso expansivo de até: (i) a depender de seu escopo, até instaura escalas de diferentes naturezas - pragmáticas, quando escopa o Subato Referencial, e retóricas, ao escopar o Conteúdo Comunicado; e (ii) até, independente de seu escopo, corresponde a uma partícula escalar absoluta.

\section{O item ainda}

Hannay, Martínez Caro e Mackenzie (2014), ao analisar o conectivo aditivo besides, em inglês, mapeiam dois usos do item em contextos argumentativos: um uso objetivo, em que besides introduz um argumento objetivo final que serve para encerrar a argumentação em andamento, e um uso (inter)subjetivo, em que besides adiciona um argumento, dotado de um ponto de vista mais (inter)pessoal, que prevalece em relação aos argumentos precedentes.

Esses duplo funcionamento de besides, no inglês, assemelha-se ao uso de ainda, enquanto marcador da função Contraste Expansivo, e correlaciona-se ao seu duplo escopo no Nível Interpessoal. Ao escopar Subatos Referenciais (cf. (17)), ainda funciona como besides objetivo: ele introduz um elemento final de uma descrição, ou melhor, o falante o emprega para seguir com sua mesma linha de raciocínio e estabelecer uma finalização para o progresso de seu discurso, isto é, sinalizar o fim de sua mensagem.

(17) a Rubinho - Analisando as ações culturais do Estado a gente não vê o que via no Governo Joaquim Francisco, que era a Fundarpe e tão somente a Fundarpe fomentando a cultura. $\mathrm{Na}$ realidade, hoje tem a Secretaria de Cultura com a embaixada que Ariano desenvolve com maestria; tem a Fundarpe executando o que a gente procurou executar, com deficiências lamentáveis de verba e que conseguiu ainda desenvolver o importante projeto O Livro Por um Real, que movimentou todo Estado. Há ainda a Secretaria de Imprensa desenvolvendo ações culturais como marketing para o Estado, como esse Festival de Cuba. Então há, na verdade, três ações culturais, três caminhos, com verbas reservadas para cada uma dessas ramificações, sem que entrem em choque. Então são três cabeças e três corpos. Eu era um corpo só. (19Or:Br:Intrv:Com)

NI: $\left(A_{1}:\left(C_{1}:\left[\left(R_{1}:-a\right.\right.\right.\right.$ Secretaria de Imprensa desenvolvendo ações culturais como marketing para o Estado, como esse Festival de Cuba - $\left.\left.\left.\left.\left(\mathrm{R}_{1}\right)_{\text {ContExp }}\right)\right]\left(\mathrm{C}_{1}\right)\right)\left(\mathrm{A}_{1}\right)\right)$

b Nos EUA, os detetives são mais uma condição do gênero. Até o próprio direito dos EUA e da Inglaterra permitiu o florescimento da profissão, coisa que é mais difícil no nosso direito romano. Aqui, Borges colocou um detetive em uma história irreal ou Osvaldo Soriano, que pega Marlowe, o detetive de Raymond Chandler e o coloca em sua novela de forma direta. Ou, ainda, novelas em que o detetive é um personagem deslocado, como um jornalista, como Renzi. Há um caso pitoresco também: ao modo do padre Brown, de 
G.K. Chesterton, que coloca um padre, está o caso de Leonardo Castelani, autor de Os Sete Casos do Padre Neri. (19Or:Br:Intrv:ISP)

NI: $\left(\mathrm{A}_{1}:\left(\mathrm{C}_{1}\right.\right.$ : $\left[\left(\mathrm{R}_{1}:-\right.\right.$ novelas em que o detetive é um personagem deslocado, como um jornalista, como Renzi - $\left.\left.\left.\left.\left(\mathrm{R}_{1}\right)_{\text {ContExp }}\right)\right]\left(\mathrm{C}_{1}\right)\right)\left(\mathrm{A}_{1}\right)\right)$

Em (17a), o falante enumera as ações culturais desenvolvidas pelo Estado e, para isso, faz referência a três órgãos: a Secretaria de Cultura, a Fundarpe e a Secretaria de Imprensa. Ainda, usado no interior de uma Construção Apresentativa, ${ }^{7}$ escopa o Subato Referencial $a$ Secretaria de Imprensa, sinalizando, então, a introdução do terceiro e último elemento a compor a descrição ali em desenvolvimento.

O mesmo se aplica a (17b): ao tratar das ficções que envolvem a figura do detetive, o falante justapõem as referências a Borges, a Osvaldo Soriano e a novelas; ainda escopa o último Subato Referencial dessa lista, inserido como alternativa final (haja vista a conjunção ou que o introduz) a integrar o discurso.

Ainda, nos dados em (17), assinala a adição (ou expansão) objetiva de novos Subatos Referenciais e, assim, não estabelece nenhum tipo de escala entre as alternativas dispostas no discurso. Não se observa, por exemplo, que a evocação dos referentes Secretaria de Imprensa e novelas em que o detetive é um personagem deslocado ocupa qualquer posição superior às outras variáveis referenciadas no discurso; trata-se, de fato, de uma expansão informacional objetiva, uma adição de um referente para integrar a mensagem do falante e fechá-la.

Isso é diferente quando ainda expansivo escopa o Conteúdo Comunicado (cf. (18)). Nesse caso, ainda funciona, conforme Hannay, Martínez Caro e Mackenzie (2014), como um marcador intersubjetivo: ele sinaliza a introdução de uma informação de especial importância para o ponto específico de desenvolvimento de seu discurso.

(18) JC - Dá para sobreviver sem promoção? Fortunato - Não. Antigamente, as liquidações eram anuais, passaram a semestrais e, hoje, têm de ser semanal. A indústria está estocada, ela oferece um lote, dá prazo e ainda paga a propaganda. A própria indústria traz a oferta. As vezes, há duas ou três no mesmo dia. As indústrias chegam a pagar de $80 \%$ a $100 \%$ a propaganda nos jornais. (19Or:Br:Intrv:Com)

NI: $\left(\mathrm{M}_{1}\right.$ : $\left[\left(\mathrm{A}_{1}:-\mathrm{a}\right.\right.$ indústria está estocada - $\left.\left(\mathrm{A}_{1}\right)\right)\left(\mathrm{A}_{2}\right.$ : - ela oferece um lote $\left.-\left(\mathrm{A}_{2}\right)\right)\left(\mathrm{A}_{3}\right.$ : - dá prazo - $\left.\left.\left(\mathrm{A}_{3}\right)\right)\right)\left(\mathrm{A}_{4}:\right.$ - ainda paga a propaganda - $\left.\left.\left.\left.\left(\mathrm{A}_{4}\right)\right)\right)\right]\left(\mathrm{M}_{1}\right)\right) \rightarrow\left(\mathbf{A}_{4}:\left(\mathbf{C}_{1}\right.\right.$ : - paga a propaganda $\left.\left.-\left(\mathrm{C}_{1}\right)_{\text {ContExp }}\right)\left(\mathrm{A}_{4}\right)\right)$

Em (18), o falante, em seu Movimento, traz um conjunto de fatos associados à indústria, e ainda escopa o último fato por ele acrescido, o de a indústria pagar a propaganda. Nesse

\footnotetext{
${ }^{7} \mathrm{Na}$ GDF, a Construção Apresentativa é um dos modos de organização do Conteúdo Comunicado. Ao servir para indicar a emergência de um novo referente no discurso, compõe-se de um único Subato Referencial, que carrega, inerentemente, a combinação das funções pragmáticas Tópico e Foco.
} 
contexto de adição impura (LENKER, 2010), há certo contraste entre o Conteúdo Comunicado de pagar a propaganda e os outros listados no contexto anterior, ou melhor, o uso de ainda sinaliza que o novo Conteúdo Comunicado apresenta estatuto saliente para encerrar o encadeamento de fatos que compõem aquele ponto específico de sua argumentação.

Assim, numa escala retoricamente estabelecida, o Conteúdo Comunicado escopado por ainda ganha, para os propósitos comunicativos do falante, uma proeminência pontual, isto é, diferentemente de até (cf. (15) e (16)), ainda não assinala um conteúdo extremo (fixo numa posição mais superior a qualquer outro argumento) para os propósitos retóricos do falante, mas, de fato, ainda atribui ao Conteúdo Comunicado relativa importância naquele cenário comunicativo. É possível observar tais questões também em (19).

(19) a Rubinho - Analisando as ações culturais do Estado a gente não vê o que via no Governo Joaquim Francisco, que era a Fundarpe e tão somente a Fundarpe fomentando a cultura. $\mathrm{Na}$ realidade, hoje tem a Secretaria de Cultura com a embaixada que Ariano desenvolve com maestria; tem a Fundarpe executando o que a gente procurou executar, com deficiências lamentáveis de verba e que conseguiu ainda desenvolver o importante projeto O Livro Por um Real, que movimentou todo Estado. Há ainda a Secretaria de Imprensa desenvolvendo ações culturais como marketing para o Estado, como esse Festival de Cuba. Então há, na verdade, três ações culturais, três caminhos, com verbas reservadas para cada uma dessas ramificações, sem que entrem em choque. Então são três cabeças e três corpos. Eu era um corpo só. (19Or:Br:Intrv:Com)

NI: $\left(\mathrm{A}_{1}\right.$ : $\left(\mathrm{C}_{1}\right.$ : - desenvolver o importante projeto O Livro Por um Real, que movimentou todo Estado - $\left.\left.\left(\mathrm{C}_{1}\right)_{\text {ContExp }}\right)\left(\mathrm{A}_{1}\right)\right)$

b Estado - Como foi que o sr. saiu da Espanha para a Resistência? Apolonio - Em outubro de 1938, o governo da república, num gesto quixotesco, dispensou as Brigadas Internacionais, para ficar provado que estrangeiros eram apenas os inimigos. Havia uns 35 mil homens e mulheres. Ainda nos incorporamos à luta contra os franquistas em Barcelona, mas fomos repelidos até a fronteira com a França, em 9 de fevereiro de 1939. Aí, depusemos as armas. (19Or:Br:Intrv:ISP)

NI: $\left(A_{1}:\left(C_{1}:-\right.\right.$ nos incorporamos à luta contra os franquistas em Barcelona - $\left(\mathrm{C}_{1}\right)$ ContExp $)$ $\left.\left(\mathrm{A}_{1}\right)\right)$

Em (19a), ainda ocorre em contextos de subordinação completiva, inserindo-se entre o verbo conseguir e sua oração completiva, que, no Nível Interpessoal, representa um Conteúdo Comunicado. Nota-se que, ao tratar da Fundarpe, ainda sinaliza a adição de uma informação bastante proeminente para caracterizar as ações do órgão. Assim, ainda instaura uma escala retórica entre as duas ações da Fundarpe ali dispostas, de modo que a de desenvolver $o$ importante projeto O Livro Por um Real, que movimentou todo Estado tem especial importância e relevância para os objetivos argumentativos do falante naquele ponto de desenvolvimento de seu discurso. Já em (19b), ao tratar dos acontecimentos que se dão em outubro de 1938, ainda escopa o Conteúdo Comunicado pelo Ato nos incorporamos à luta à 
contra os franquistas em Barcelona, o que, de certa forma, assinala, a esse conteúdo, um estatuto comunicativo especial para o desenrolar daquele ponto inicial da narração.

O uso expansivo de ainda, com escopo sobre o Conteúdo Comunicado, não assinala, portanto, o argumento, ou o conteúdo, mais extremo para o desenvolvimento da direção argumentativa do discurso, mas traz um conteúdo relativamente importante para, de alguma maneira, efetivar o movimento retórico do falante. Dessa maneira, nota-se que ainda expansivo, ao escopar o Conteúdo Comunicado, instaura escalas retóricas e funciona como uma partícula escalar relativa, isto é, seguindo Schwenter (2000; 2002), ainda expansivo não marca inerentemente o ponto final de uma escala retórica, apenas situa um argumento como especial e proeminente para um ponto específico de seu discurso.

\section{Considerações finais}

Este artigo, ao mapear as distintas relações de escopo contraídas por até e ainda, no Nível Interpessoal, enquanto marcador da função pragmática Contraste Expansivo, chega às seguintes conclusões em relação à expressão de escalaridade no português:

até corresponde, nos termos de Schwenter (2000; 2002), a uma partícula escalar absoluta, situando a informação por ele escopada em posição superior e extrema no interior de uma escala. Ao escopar um Subato Referencial, até situa o referente evocado numa posição mais extrema no interior de uma escala pragmática, cujos membros se ordenam conforme relações de implicação pragmática. Já ao escopar um Conteúdo Comunicado, até sinaliza que esse conteúdo é o mais extremo no interior de uma escala retórica, isto é, trata-se de um argumento mais central e mais proeminente para sustentar a argumentação e os propósitos comunicativos do falante;

(ii) ainda, no Nível Interpessoal, contrai relações de escopo com o Subato Referencial e com o Conteúdo Comunicado, mas é somente com o último que implica escalas de natureza retórica, funcionando como uma partícula escalar relativa. Assim, ao escopar um Conteúdo Comunicado, ainda assinala relativa importância comunicativa a um argumento dentro de um cenário comunicativo pontual; não se trata, portanto, de assinalar a informação mais central para a argumentação do falante, mas sim de sinalizar a relativa importância que "ganha" certo conteúdo num ponto específico da argumentação do falante.

Assim, ao marcar adição, ou expansão, informacional, até e ainda se distinguem, funcionalmente, em termos de efeitos escalares. Se a expansão informacional constitui um novo Subato Referencial, até situa o referente num ponto extremo de uma escala pragmática, enquanto ainda não efetiva qualquer tipo de escalonamento. Já quando a expansão informacional corresponde a um novo Conteúdo Comunicado, até a coloca num ponto extremo de uma escala retórica, e ainda apenas sinaliza sua proeminência comunicativa, sem necessariamente a situar num ponto extremo da escala retórica implicada. 
Um último ponto a se considerar, neste artigo, é que a análise aqui implementada demonstra a viabilidade de se mapear as diferentes relações de escopo, em termos de camadas e níveis da GDF, contraídas por partículas escalares para o estudo da escalaridade, como mecanismo específico de determinação de distintos efeitos escalares acarretados pelo seu uso.

\section{Referências}

BAIÃO, R. B.; ARRUDA, J. Gramaticalização de até. In: MARTELOTTA, M. E.; VOTRE, S. J.; CEZARIO, M. M. Gramaticalização no português do Brasil: uma abordagem funcional. Rio de Janeiro: Tempo Brasileiro/UFRJ, 1996.

BAKKER, E. J. Linguistics and formulas in Homer: scalarity and the description of the particle per. Amsterdam/Philadelphia: John Benjamins Publishing Company, 1988.

FAUCONNIER, G. Pragmatic scales and logical structure. Linguistic Inquiry, v. 4, p. 353$375,1975$.

FONTES, M. G. A distinção léxico-gramática na Gramática Discursivo-Funcional: uma proposta de implementação. 2016. 236 f. Tese (Doutorado em Estudos Linguísticos) Programa de Pós-Graduação em Linguística, Universidade Estadual Paulista, São José do Rio Preto, 2016.

GAZDAR, G. Pragmatics: Implicature, Presupposition, and Logical Form. New York: Academic Press, 1979.

GRICE, H. P. Lógica e conversação. In: DASCAL, M. (Org.). Fundamentos metodológicos da linguística. v. 4: Pragmática. Trad. João W. Geraldo. São Paulo: Global, 1982.

HANNAY, M.; MARTÍNEZ CARO, E.; MACKENZIE, J. L. Besides as a connective. In: GÓMEZ GONZÁLEZ, M. A.; RUIZ DE MENDOZA-IBÁÑEZ, F.; GONZÁLVEZ GARCÍA, F.; DOWNING, A. (Eds.). The Functional Perspective on Language and Discourse: Applications and Implications. Amsterdam; Philadelphia: John Benjamins, 2014. p. 223-242.

HENGEVELD, K. A hierarchical approach to grammaticalization. In.: HENGEVELD, K.; NARROG, H.; OLBERTZ, H. (Eds.). The Grammaticalization of Tense, Aspect, Modality, and Evidentiality from a Functional Perspective. Berlin: Mouton de Gruyter, 2017. p. 1338 .

HENGEVELD, K.; MACKENZIE, J. L. Functional Discourse Grammar: a typologicallybased theory of language structure. Oxford: Oxford University Press, 2008.

HORN, L.R. On the Semantic Properties of Logical Operators in English. Indiana University Linguistics Club, 1972.

KÖNIG, E. The Meaning of Focus Particles. London: Routledge, 1991. 
LENKER, U. Argument and Rhetoric Adverbial Connectors in the History of English. Berlin/New York: Walter de Gruyter, 2010.

PEZATTI, E. G. A ordem das palavras no português. São Paulo: Parábola Editorial, 2014.

SCHWENTER, S. A. Pragmatics of Conditional Marking: Implicature, Scalarity, and Exclusivity. New York: Garland, 1999.

SCHWENTER, S. A. Lo relativo y lo absoluto de las partículas escalares incluso y hasta. Oralia, n. 3, p. 169-197, 2000.

SCHWENTER, S. A. Additive particles and scalar endpoint marking. Belgian Journal of Linguistics, v. 16, p. 119-134, 2002.

SCHWENTER, S.; TRAUGOTT, E. Invoking scalarity: the development of in fact. Journal of Historical Pragmatics, v. 1, n. 1, p. 7-25, 2000.

TRAVAGLIA, L. C. O relevo no processamento da informação. In: JUBRAN, C. C. S.; KOCH, I. G. V. (Orgs.). Gramática do português culto falado no Brasil: construção do texto falado. Campinas: Editora da UNICAMP, 2006. p. 167-215.

\section{Sobre os autores}

Michel Gustavo Fontes (Orcid iD: http://orcid.org/0000-0003-2376-8648)

Doutor e mestre em Estudos Linguísticos pela Universidade Estadual Paulista (UNESP); graduado em Letras - Português/Espanhol pela mesma instituição. É professor na graduação e no Programa de Pós-Graduação em Letras da Universidade Federal de Mato Grosso do Sul (UFMS), câmpus de Três Lagoas.

Fábio de Lima Moreira (Orcid iD: http://orcid.org/0000-0003-3313-9167)

Mestrando no Programa de Pós-Graduação em Letras da Universidade Federal de Mato Grosso do Sul (UFMS); graduado em Letras - Português/Inglês pela mesma instituição.

Recebido em junho de 2020.

Aprovado em agosto de 2020. 